\title{
Adiponectin Supports Human Glioma Cells Survival against Temozolomide through Enhancement of Autophagic Response in Glioma Cells
}

\author{
Peng Sun ${ }^{1}$, Feng Yan ${ }^{2}$, Jinning Song ${ }^{*}$, Xudong Ma1 \\ ${ }^{1}$ Department of Neurosurgery, The First Affiliated Hospital of Xi'an Jiaotong University, Xi'an, China \\ ${ }^{2}$ Department of Nutrition, The Xijing Hospital, Fourth Military Medical University, Xi'an, China \\ Email: "peng_s@163.com
}

Received 18 February 2016; accepted 20 March 2016; published 24 March 2016

Copyright (C) 2016 by authors and Scientific Research Publishing Inc.

This work is licensed under the Creative Commons Attribution International License (CC BY).

http://creativecommons.org/licenses/by/4.0/

(c) (1) Open Access

\begin{abstract}
Objective: To investigate the role of adiponectin in human glioma cell lines against the temozolomide and the molecular regulation mechanism. Methods: Human glioma cell lines U251 and U-87MG were cultured in Dulbecco's modified eagle medium (DMEM) containing $4500 \mathrm{mg} / \mathrm{L}$ glucose. MTT was used to measure cell growth ratio. Western blot was used to detect the protein levels of autophagy-related protein (Beclin 1, LC3 I/II, p62) and phosphorylated AMPK (p-AMPK) in human glioma cell lines. After AICAR and Compound $C$ were administered, the change of p-AMPK and the autophagy level were examined by western blot. Results: While adiponectin stimulates AMPK in phosphatase and up-regulates the level of autophagy, human glioma cell lines obtain more resistance against the temozolomide, which is facilitated by AICAR and weakened by Compound C. Conclusion: As an important adipokine, adiponectin can up-regulate the glioma cell autophagy by activating the AMPK signaling pathway which increases the resistance of glioma cells to temozolomide.
\end{abstract}

Keywords

Human Glioma Cell Lines, Adiponectin, Autophagy, Temozolomide, AMPK

\section{Introduction}

Human Glioma is one of the most common malignancies in central nervous system and accounts for $20 \%-40 \%$ ${ }^{*}$ Corresponding author.

How to cite this paper: Sun, P., Yan, F., Song, J.N. and Ma, X.D. (2016) Adiponectin Supports Human Glioma Cells Survival against Temozolomide through Enhancement of Autophagic Response in Glioma Cells. Journal of Biosciences and Medicines, 4, 1-9. http://dx.doi.org/10.4236/jbm.2016.44001 
intracranial tumors. At present, the treatment of glioma is mainly surgical resection, combined with radiotherapy, chemotherapy and other comprehensive treatments, but the overall therapeutic effectiveness is discontented with high recurrence rate and the poor prognosis [1] [2]. On the premise of excising the tumor completely, improving the sensitivity of radiotherapy and chemotherapy has become the main treatment strategy. Recently adiponectin, an important member of the adipokines, has be certified to inhibit the proliferation and promote the apoptosis of breast cancer, prostate cancer, colorectal cancer and other tumor cells, and consequently to be a significant factor which restrains the growth of tumor [3]-[7]. However, some studies indicated that, in the hypoxic state, adiponectin could increase the survival rate of rectal cancer cells by up-regulating the level of autophagy [8]. Liu Lei et al. [9] proved that autophagy could enhance tumor cells' resistance to chemotherapeutic drugs. Researches for adiponectin and glioma are still deficient. So that adiponectin could increase the resistance of glioma cells to temozolomide by up-regulating autophagy needs to be further verified. This study used human glioma cell lines U-87MG and U251 as the research object and detected the role of adiponectin in human glioma cell lines against the temozolomide and the molecular regulation mechanism.

\section{Materials and Methods}

\subsection{Reagents and Cell Culture}

Recombinant human full-length adiponectin/Acrp30 was purchased from R\&D Systems (USA). AICAR and Compound C were received from Sigma (USA) and dissolved in Dimethyl sulfoxide (DMSO) (from sigma, USA). 3-(4,5)-dimethylthiahiazo (-z-y1)-3,5-diphenytetrazoliumromide; Thiazolyl blue (MTT) was from Sigma(UK). Temozolomide (TMZ) and antibodies against adiponectin receptor 2 were from abcom (USA). Antibodies against adiponectin receptor 1, LC3 I/II, becline 1, p62, AMPK, p-AMPK were purchased from Cell Signal Technology (CST) (USA). U-87MG and U251 cells were obtained from the American Type Culture Collection(USA) and were grown in Dulbecco's modified eagle medium (DMEM) containing $4500 \mathrm{mg} / \mathrm{L}$ glucose, $1 \%$ penicillin/streptomycin with $10 \%$ foetal bovine serum (FBS) (all from Hyclone, USA) in $5 \% \mathrm{CO}_{2} / 95 \%$ air at $37^{\circ} \mathrm{C}$. Cells were subcultured following enzymatic digestion using trypsin/EDTA solution (Hyclone, USA).

\subsection{Cell Growth Ratio Assay}

The MTT was dissolved in PBS solution at a concentration of $5 \mathrm{mg} / \mathrm{ml}$ and filtered through a $0.22 \mu \mathrm{m}$ filter to sterilize and remove insoluble residues, and then stored in the amber vials at $4^{\circ} \mathrm{C}$ for a month. After 48 and $72 \mathrm{~h}$ incubation, $20 \mu \mathrm{l}$ of the MTT solution was added to each well of 96-well plates and incubated for $4 \mathrm{~h}$ at $37^{\circ} \mathrm{C}$ in a humidified atmosphere of $5 \% \mathrm{CO}_{2}$. At end of the incubation period, DMSO was added to each well of 96-well plates for removing insoluble residues. The absorbance was determined at $490 \mathrm{~nm}$. The A490 was taken as an index of the cell viability and the activity of mitochondria. The net absorbance from the plates of cells cultured with the control medium (not treated) was considered as $100 \%$ of the cell growth ratio and the mitochondrial activity.

\subsection{Western Blot}

The expression of adiponectin receptor 1, adiponectin receptor 2, LC3 I/II, becline 1, p62, AMPK, p-AMPK were determined by western blotting. Total protein content in each lane was determined using the bicinchoninic acid assay and then each lane containing equal amounts of protein were separated on a $10 \%$ - 15\% SDSP-AGE gel. After transfer to nitrocellulose membranes, blots were blocked with $5 \%$ nonfat milk in $0.2 \%$ Tween 20 in Tris-buffered saline (TBS) for $1 \mathrm{~h}$ and then incubated with primary antibody at $4^{\circ} \mathrm{C}$ overnight. Blots were then washed five times for $10 \mathrm{~min}$ in washing buffer (0.2\% Tween 20 in TBS), followed by incubation for $2 \mathrm{~h}$ at room temperature with a specific secondary antibody. Subsequently, these specific antibodies were detected by using ECL Western blotting detection (Millipore, USA) and the fluorescence excitation was imaged on X-ray film. Normalization was based on the protein level of GAPDH and analyzed by Imagine J software.

\subsection{Statistical Analysis}

All statistical analysis was performed using SPSS 13.0 (SPSS Inc. USA). All data were presented as mean \pm SEM. All data were analyzed by analysis of t-test when normality and homogeneity of variance assumptions are 
satisfied. Significance was set at $P<0.05$.

\section{Result}

\subsection{The Expression of the Adiponectin Receptor in Glioma Cell Lines}

Adiponectin can't display biological functions until adiponectin is combinated with adiponectin receptor (ADIPOR), locating on cell membrane surface. There are both ADIPOR1 and ADIPOR2 expression (Figure 1) in glioma cell lines U251and U-87MG detected by WB, which is the basis for further study.

\subsection{Adiponectin Dose-Response and Time-Response Experiments}

$5 \times 10^{3}$ cells per well were seeded in 96 well plates in $1 \%$ FBS containing medium for $24 \mathrm{~h}$. Cells were subsequently treated with increasing concentrations ( $0 \mu \mathrm{g} / \mathrm{ml}, 0.1 \mu \mathrm{g} / \mathrm{ml}, 0.5 \mu \mathrm{g} / \mathrm{ml}, 1 \mu \mathrm{g} / \mathrm{ml}, 3 \mu \mathrm{g} / \mathrm{ml}, 10 \mu \mathrm{g} / \mathrm{ml})$ of adiponectin and incubated for a further $24 \mathrm{~h}$. we assessed the cell growth ratio of the human glioma cell line, U251 and U87-MG, by MTT assay. It has been discovered that adiponectin at $3 \mu \mathrm{g} / \mathrm{ml}$ reliably produced near maximal stimulation and was used for subsequent mechanistic studies $(P<0.05$, Figure 2(a)). After serum

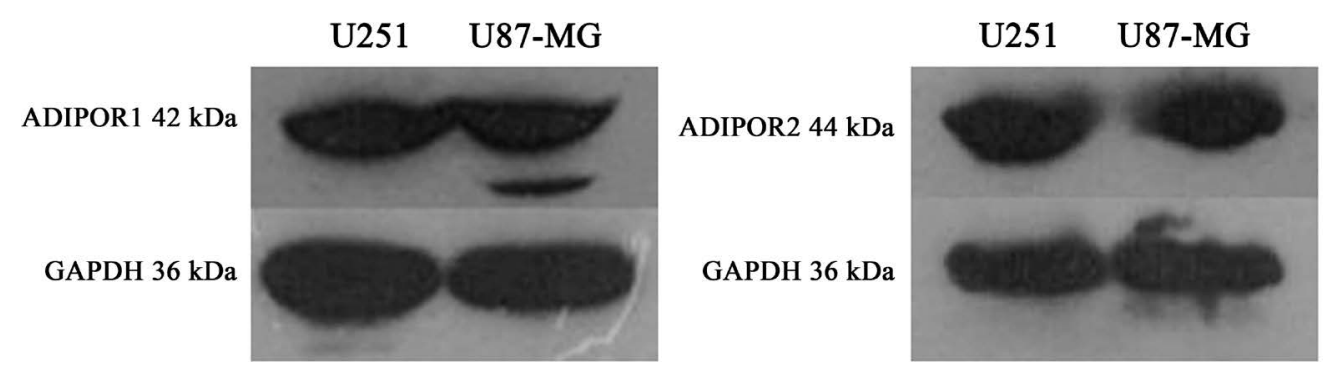

Figure 1. The expression of the adiponectin receptor in U251 and U-87MG.

(a)

$\mathrm{U} 251$
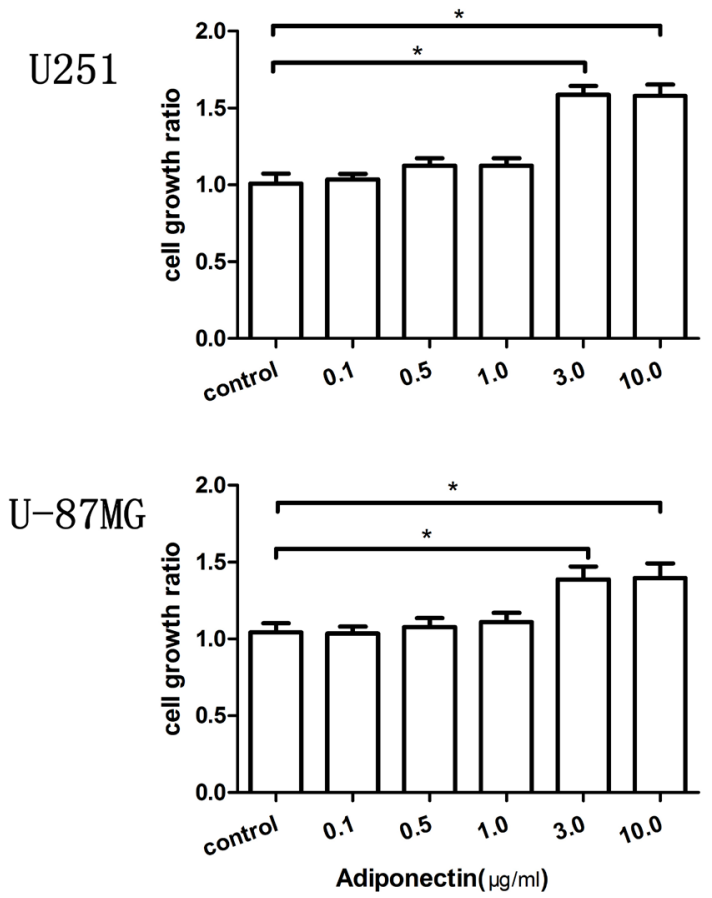

(b)
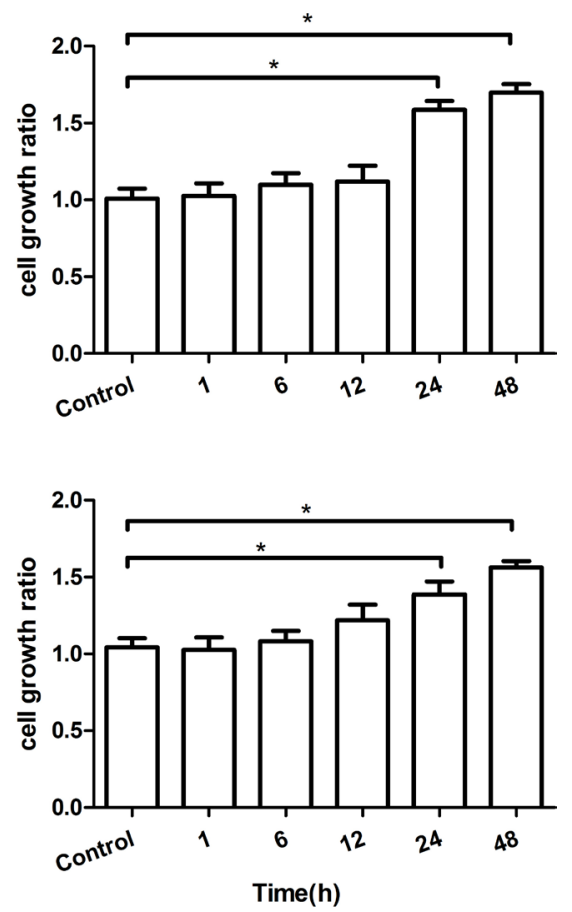

Figure 2. Effect of adiponectin on U251 and U-87MG cells proliferation (a) U251 and U-87MG cells were cultured with increasing concentrations of adiponectin for $24 \mathrm{~h}$. (b) U251 and U-87MG cells were treat with $3 \mu \mathrm{g} / \mathrm{ml}$ adiponectin for a different time course. Cell growth ratio was assessed by MTT assay. Mean $\pm \mathrm{SEM}, \mathrm{N}=6,{ }^{*} \mathrm{P}<0.05$ versus untreated control. 
starvation for $24 \mathrm{~h}$, U251 and U-87MG cells were treat with $3 \mu \mathrm{g} / \mathrm{ml}$ adiponectin for a different time course $(1 \mathrm{~h}$, $6 \mathrm{~h}, 12 \mathrm{~h}, 24 \mathrm{~h}, 48 \mathrm{~h}$ ). We find that adiponectin in the time course, $24 \mathrm{~h}$, reliably produced near maximal stimulation and was used for subsequent mechanistic studies $(P<0.05$, Figure 2(b)).

\subsection{Effect of Adiponectin on the Expression of Autophagy Related Protein in Human Glioma Cells}

The protein levels of autophagy in U251 and U-87MG cells were determined by Western blotting. After being incubated with $3 \mu \mathrm{g} / \mathrm{ml}$ adiponectin for $24 \mathrm{~h}$, compared to the control group, the expression of Beclin 1 and the ratio of LC3 II/I were significantly increased, the expression of p62 was sharply reduced (Figure 3(a)). Gray
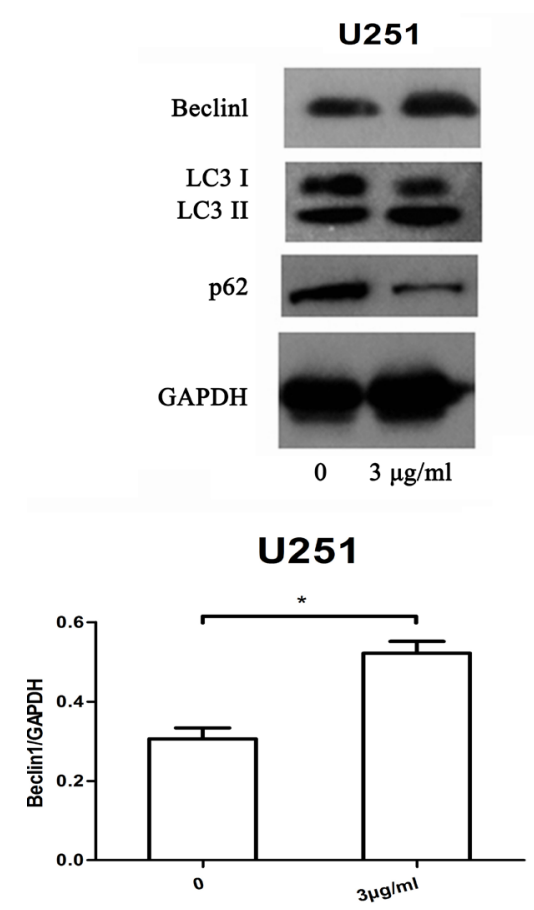

(a)
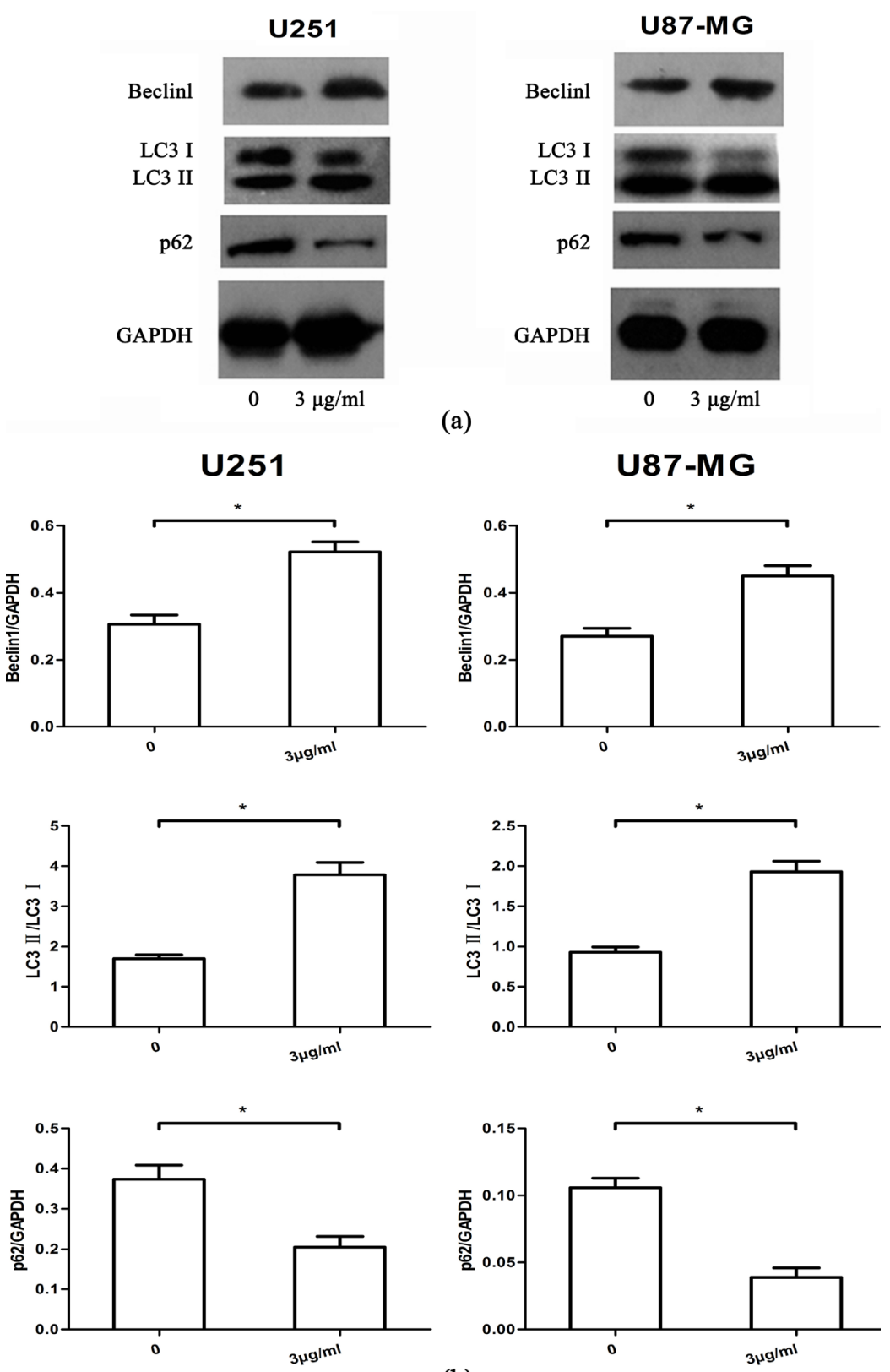

(b)

Figure 3. Changes of autophagy related protein after being treated with $3 \mu \mathrm{g} / \mathrm{ml}$ adiponectin for $24 \mathrm{~h}$ in U251 and U-87MG cells. (a) Western blot; (b) gray value analysis. The expression of Beclin1 and the ratio of LC3 II/I were significantly increased, and the expression of p62 was sharply reduced. ${ }^{*} P<0.05$ versus untreated control. 
value analysis by Image J showed that the expression of autophagy related proteins (Beclin1, LC3, p62) in the 3 $\mu \mathrm{g} / \mathrm{ml}$ group compared with the untreated group has statistical difference $(P<0.05$, Figure $3(\mathrm{~b}))$.

\subsection{Effect of Adiponectin on the Expression of AMPK in Human Glioma Cells}

We detected the expression of AMPK and p-AMPK in glioma cells by Western blotting. U251 and U-87MG cells were incubated with $3 \mu \mathrm{g} / \mathrm{ml}$ adiponectin for a different time course. The expression of p-AMPK began to be increased at $12 \mathrm{~h}$ and reached the peak at $24 \mathrm{~h}$ (Figure 4(a)). Gray value analysis showed that compared to the control group, the expression of p-AMPK was significantly increased respectively after being incubated with adiponectin for $12 \mathrm{~h}, 24 \mathrm{~h}, 48 \mathrm{~h}$. The difference had statistically significant $(P<0.05$, Figure 4(b)).

\subsection{Effect of Activating or Inhibiting AMPK Signal Pathway on Autophagy of Glioma Cells Incubated with Adiponectin}

WB showed that AICAR can increase the AMPK phosphorylation and the expression of autophagy related protein Beclin1 of glioma cell after being incubated with adiponectin, and gray value analysis showed that the expression of p-AMPK and Beclin were significantly increased in Ad + AICAR group compared to the control group; CC can reduce the AMPK phosphorylation and the expression of autophagy related protein of glioma cell after being incubated with adiponectin. Gray value analysis also showed that the expression of p-AMPK and Beclin were significantly reduced in Ad + CC group compared to the control group. The difference had statistically significant $(P<0.05$, Figure 5).

\subsection{Adiponectin Increases the Resistance of Glioma Cells to Temozolomide}

We added different concentrations of temozolomide into culture medium after seeding plated the glioma cells
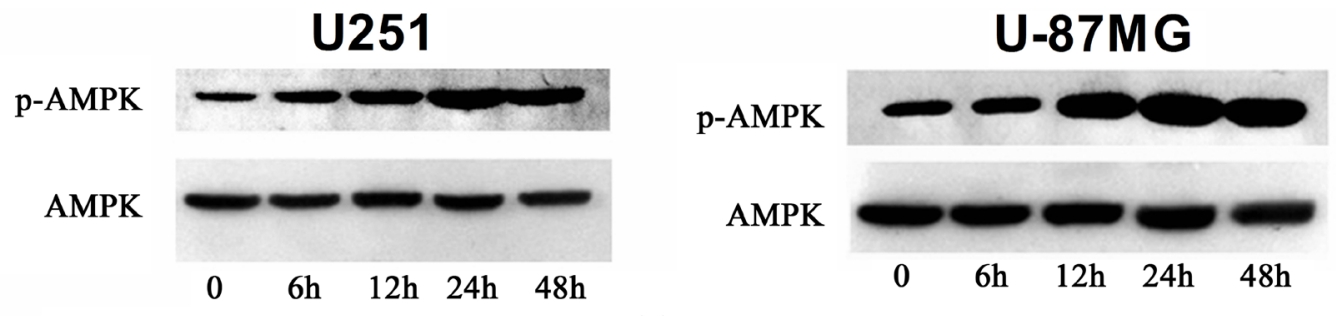

(a)

\section{U251}
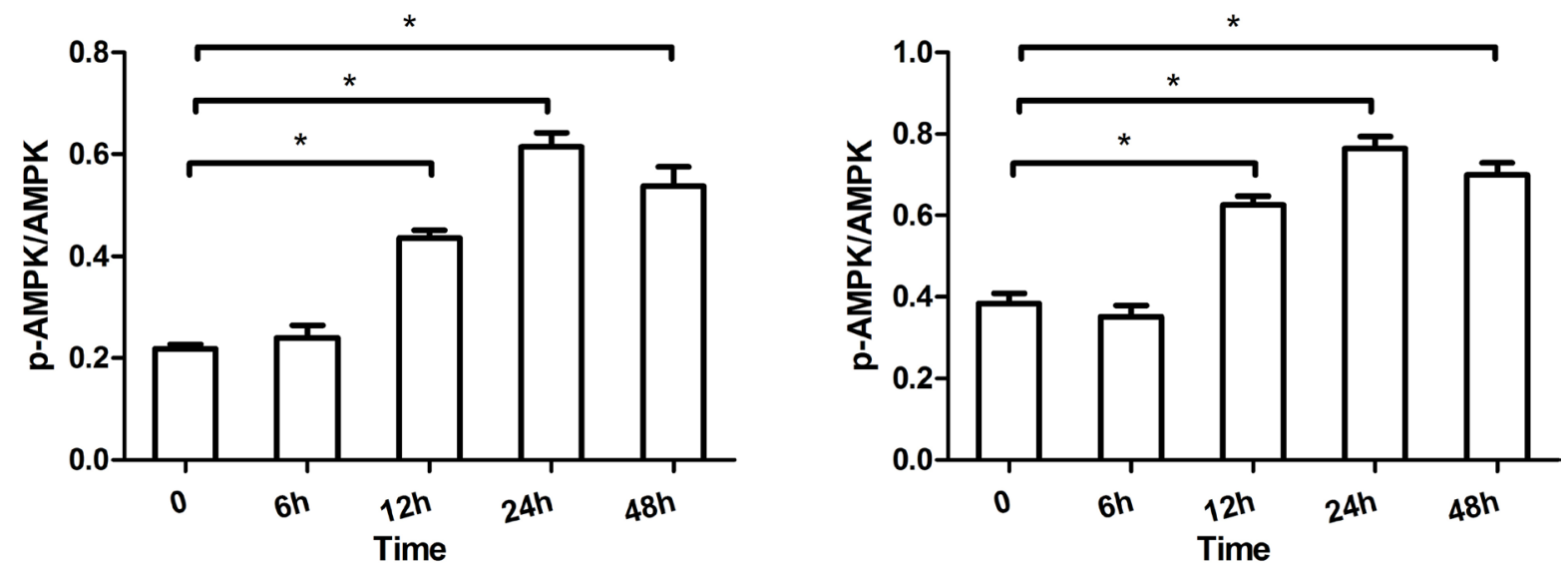

(b)

Figure 4. The time course of activation of AMPK determined by western blot in U251 and U-87MG cells after treated with adiponectin. (a) Western blot; (b) gray value analysis. The ratio of p-AMPK to AMPK were increased and peaked at $24 \mathrm{~h}$ after treated with adiponectin. ${ }^{*} P<0.05$ versus untreated control. 


\section{$\mathrm{U} 251$}

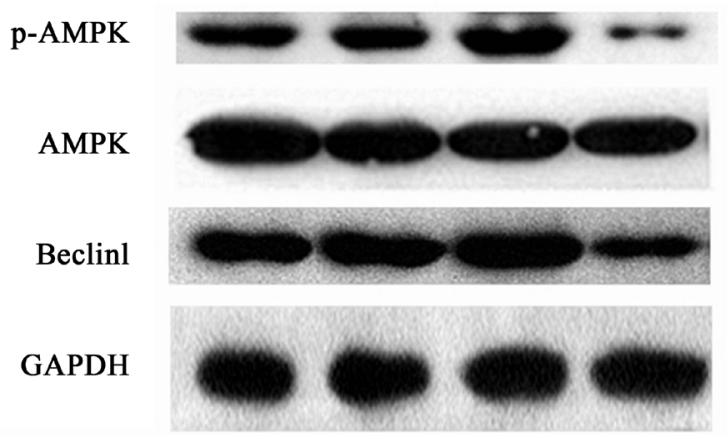

Ad Ad+vehicle Ad+AICAR Ad+CC

(a)

\section{$\mathrm{U}-87 \mathrm{MG}$}

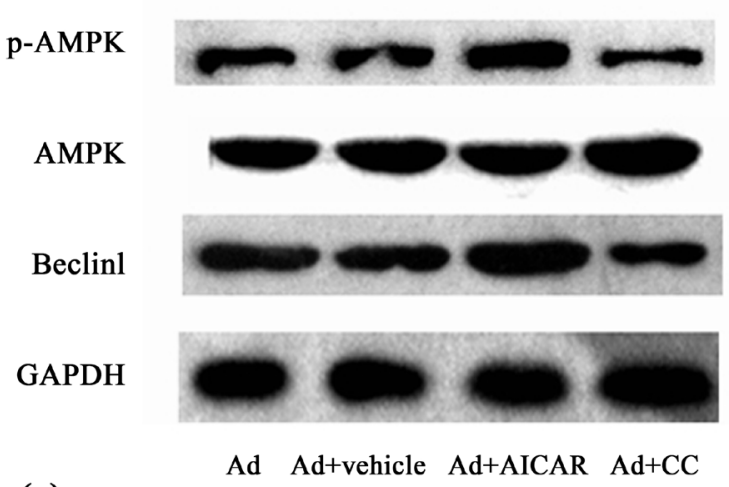

$\mathrm{U}-87 \mathrm{MG}$
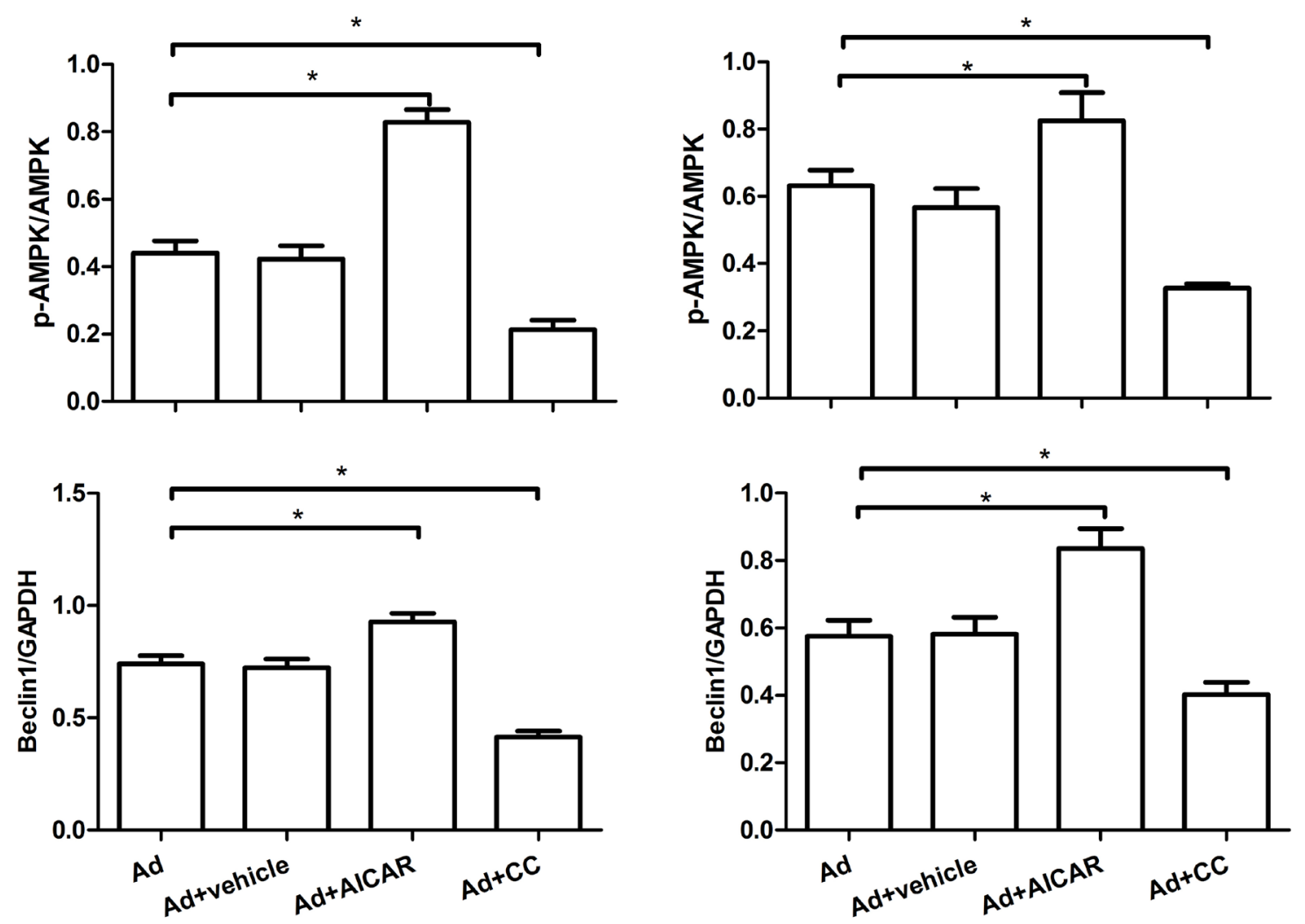

(b)

Figure 5. Effect of AICAR and CC on AMPK activation and the expression of Beclin1 in U251 and U-87MG cells after treated with adiponectin. (a) Western blot; (b) gray value analysis. The expression of p-AMPK and Beclin were significantly increased in Ad + AICAR group and sharply reduced in Ad + CC group compared to the control group. Ad: $3 \mu \mathrm{g} / \mathrm{ml}$ adiponectin; ${ }^{*} P<0.05$ versus untreated control.

for $48 \mathrm{~h}$ and found that $100 \mu \mathrm{M}, 1 \mathrm{mM}$ temozolomide can significantly reduced the cell survival rate $(P<0.05$, Figure 6). After adding $1 \mathrm{mM}$ temozolomide for $24 \mathrm{~h}$, we added $0 \mu \mathrm{g} / \mathrm{ml}, 1 \mu \mathrm{g} / \mathrm{ml}, 3 \mu \mathrm{g} / \mathrm{ml}, 10 \mu \mathrm{g} / \mathrm{ml}$ adiponectin respectively for another $24 \mathrm{~h}$ and tested the cell growth ratio by MTT. Adiponectin can enhance the resistance of glioma cells to temozolomide, and this biological effect of adiponectin was facilitated by AICAR and 
weakened by Compound C ( $P<0.05$, Figure 6(c), Figure 6(d)).

\section{Discussion}

Adiponectin, which is an important adipokine, is known to be a key molecule in the positive correlation between obesity and cancer, such as breast cancer, prostate cancer and colorectal cancer [3]-[7]. Previous studies have shown that adiponectin is a tumor suppressor that can inhibit the occurrence of tumor [8]. Our understanding of the relationship between glioma and obesity is uncertain yet. Furthermore, effects of adiponectin on glioma were poorly reported. In this research, we used U251 and U87-MG glioma cell lines to explore the role of adiponectin in human glioma cell lines against the temozolomide, in order to illustrate adiponectin can up-regulate glioma cells autophagy and increase the resistance to the chemotherapeutic drug temozolomide.

Autophagy is a homeostatic and evolutionarily conserved process, which degrades cellular contents containing useless macromolecules such as long-lived proteins, faulty aggregates or misfolded proteins, as well as damaged or redundant organelles such as mitochondria, endoplasmic reticulum, or peroxidase, in order to maintain the the cell homeostasis [10]-[14]. In mammalian cells, the process that Beclin1 isolates from Bcl-2 and combines with PI3K is a key step to initiate autophagy. After being sheared and modified by Atg7 and Atg3,

U251

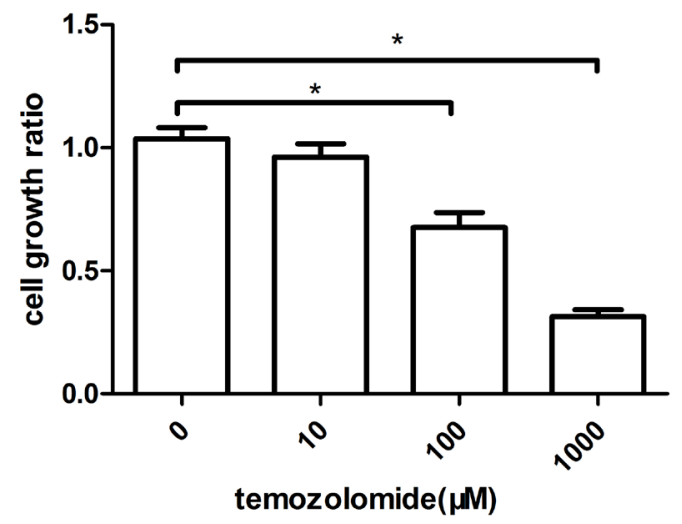

(a)

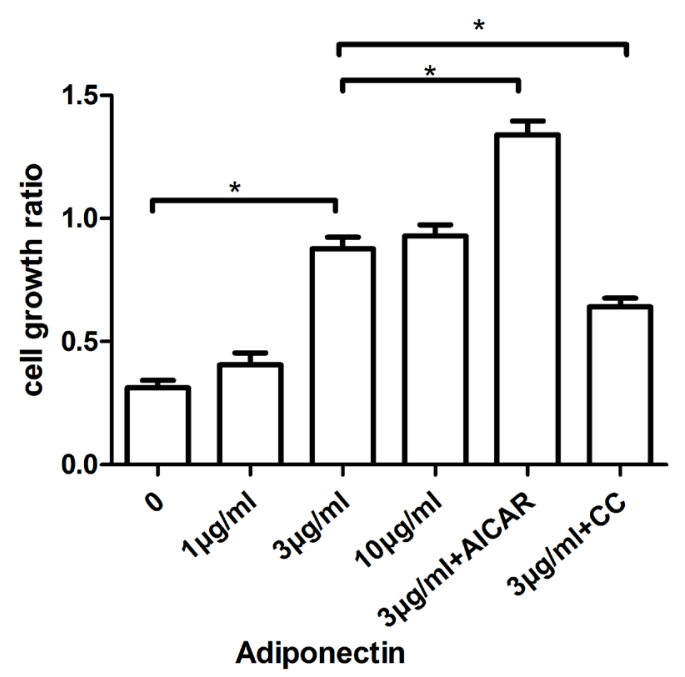

(c)
U-87MG

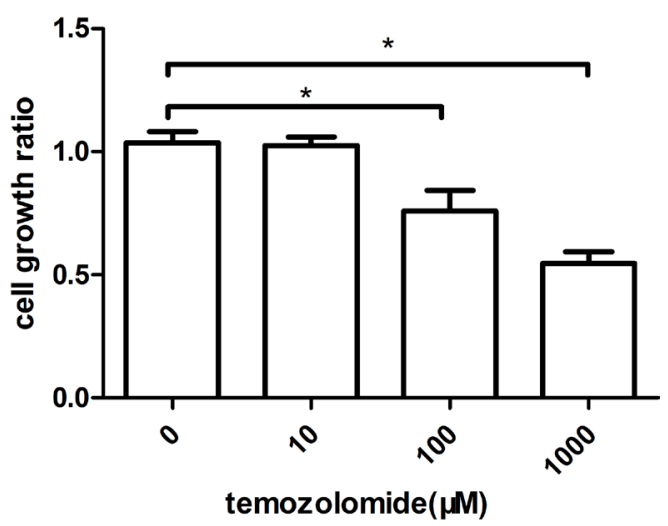

(b)

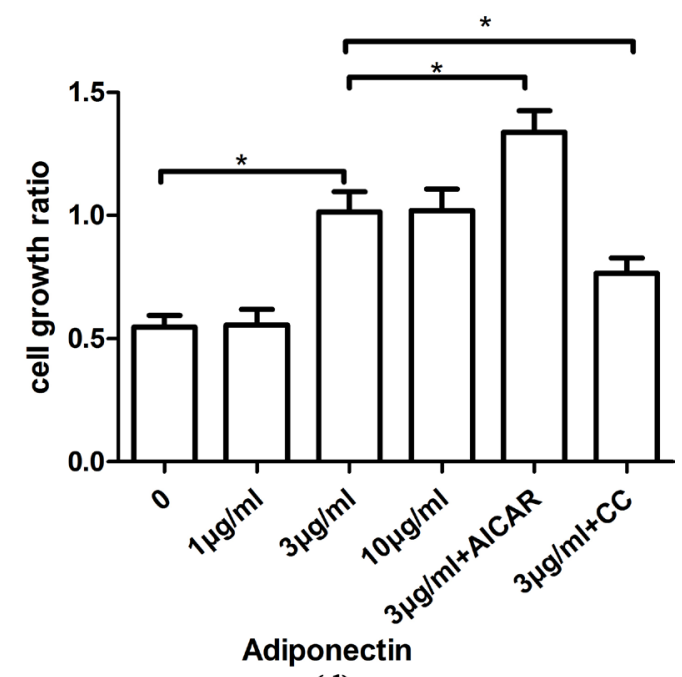

(d)

Figure 6. Changes of the resistance of glioma cells to temozolomide after treating with adiponectin. ((a), (b)) $100 \mu \mathrm{M}, 1 \mathrm{mM}$ temozolomide can significantly reduced the cell growth ratio. ((c), (d)) Adiponectin can enhance the resistance of glioma cells to temozolomide, and this biological effects of adiponectin was facilitated by AICAR and weakened by Compound C. Mean \pm SEM, $N=6,{ }^{*} P<0.05$. 
LC3 I becoming LC3 II is the specific process of autophagy, so that the ratio of LC3 II/I is regarded as an important indicator of the formation of autophagosome. The directly combination of p62 and LC3 is involved in the autolysosome's development. If large number of autophagosome formed in cells without p62 consumption, it suggests that the formation of autolysosome was restrained and autophagy was inhibited [15]. This reaserch found that adiponectin can up-regulate the expression of Beclin1 in glioma cells, increase the ratio of LC3 II/I and consume a large amount of p62, so it can be considered that adiponectin can promote the autophagy in glioma cells. In addition, adiponectin, adding into the cell culture medium, can stimulate AMPK in phosphatase and increase the expression of Beclin1 simultaneously in glioma cells. This step was facilitated by AICAR and weakened by Compound C. So it can be considered that the mechanism of adiponectin up-regulating the level of autophagy in glioma cells is related to the activation of AMPK signaling pathway, which consists with the previous conclusion that AMPK is an important target for the activation of autophagy.

Autophagy plays a double-edged sword role in the occurrence and development of tumor and has different effects in the different stages of the tumor. Autophagy limits tumor formation by preventing the accumulation of damaged proteins and organelles; after tumor formated, autophagy promotes tumor cell survival. In the process of treatment with chemotherapy drugs, autophagy makes a positive sense for the cancer cells to survive and adapt to changes in the external environment. As a result, autophagy presents a cell protection function what we don't want to see—enhancing the tumor cells resistance to chemotherapeutic drugs [14] [16] [17]. Compared to glioma cells incubated only with temozolomide for $48 \mathrm{~h}$, the growth ratio of glioma cells, which were incubated with temozolomide for $24 \mathrm{~h}$ and added adiponectin for another $24 \mathrm{~h}$, was significantly increased. What's more, AICAR and compound C interfering the above effects further. It is illustrated that adiponectin up-regulated the glioma cell autophagy by activating the AMPK signaling pathway which increased the resistance of glioma cells to temozolomide.

\section{Conclusion}

As an important adipokine, adiponectin can up-regulate the glioma cell autophagy by activating the AMPK signaling pathway, which increases the resistance of glioma cells to temozolomide. The biological effects of adiponectin are thought to be clinically important in the pathophysiology of tumor development and progression.

\section{References}

[1] Jeremias, I., Steiner, H.H., Benner, A., Debatin, K.M. and Herold-Mende, C. (2004) Cell Death Induction by Betulinic Acid, Ceramide and TRAIL in Primary Glioblastoma Multiforme Cells. Acta Neurochirurgica (Wien), 146, 721-729. http://dx.doi.org/10.1007/s00701-004-0286-4

[2] Hollon, T., Hervey-Jumper, S.L., Sagher, O. and Orringer, D.A. (2015) Advances in the Surgical Management of Low-Grade Glioma. Seminars in Radiation Oncology, 25, 181-188. http://dx.doi.org/10.1016/j.semradonc.2015.02.007

[3] Sugiyama, M., Takahashi, H., Hosono, K., Endo, H., Kato, S., Yoneda, K. et al. (2009) Adiponectin Inhibits Colorectal Cancer Cell Growth through the AMPK/mTOR Pathway. International Journal of Oncology, 34, 339-344.

[4] Cong, L., Gasser, J., Zhao, J., Yang, B., Li, F. and Zhao, A.Z. (2007) Human Adiponectin Inhibits Cell Growth and Induces Apoptosis in Human Endometrial Carcinoma Cells, HEC-1-A and RL95 2. Endocrine-Related Cancer, 14, 713-720. http://dx.doi.org/10.1677/ERC-07-0065

[5] Dos, S.E., Benaitreau, D., Dieudonne, M.N., Leneveu, M.C., Serazin, V., Giudicelli, Y., et al. (2008) Adiponectin Mediates an Antiproliferative Response in Human MDA-MB 231 Breast Cancer Cells. Oncology Reports, 20, 971-977.

[6] Barb, D., Neuwirth, A., Mantzoros, C.S. and Balk, S.P. (2007) Adiponectin Signals in Prostate Cancer Cells through Akt to Activate the Mammalian Target of Rapamycin Pathway. Endocrine-Related Cancer, 14, 995-1005. http://dx.doi.org/10.1677/ERC-06-0091

[7] Hebbard, L. and Ranscht, B. (2014) Multifaceted Roles of Adiponectin in Cancer. Best Practice \& Research Clinical Endocrinology \& Metabolism, 28, 59-69. http://dx.doi.org/10.1016/j.beem.2013.11.005

[8] Habeeb, B.S. Kitayama, J. and Nagawa, H. (2011) Adiponectin Supports Cell Survival in Glucose Deprivation through Enhancement of Autophagic Response in Colorectal Cancer Cells. Cancer Science, 102, 999-1006. http://dx.doi.org/10.1111/j.1349-7006.2011.01902.x

[9] Liu, L., Yang, M., Kang, R., Wang, Z., Zhao, Y., Yu, Y. et al. (2011) HMGB1-Induced Autophagy Promotes Chemotherapy Resistance in Leukemia Cells. Leukemia, 25, 23-31. http://dx.doi.org/10.1038/leu.2010.225

[10] Glick, D. Barth, S. and Macleod, K.F. (2010) Autophagy: Cellular and Molecular Mechanisms. Journal of Pathology, 
221, 3-12. http://dx.doi.org/10.1002/path.2697

[11] Ryter, S.W. and Choi, A.M. (2015) Autophagy in Lung Disease Pathogenesis and Therapeutics. Redox Biology, 4, 215225. http://dx.doi.org/10.1016/j.redox.2014.12.010

[12] Levine, B. and Kroemer, G. (2008) Autophagy in the Pathogenesis of Disease. Cell, 132, 27-42. http://dx.doi.org/10.1016/j.cell.2007.12.018

[13] Mizushima, N., Levine, B., Cuervo, A.M. and Klionsky, D.J. (2008) Autophagy Fights Disease through Cellular SelfDigestion. Nature, 451, 1069-1075. http://dx.doi.org/10.1038/nature06639

[14] Corcelle, E.A., Pietri, P. and Marja, J. (2009) Apoptosis and Autophagy: Targeting Autophagy Signaling in Cancer Cells_-“Trick or Treats”? FEBS Journal, 276, 6084-6096. http://dx.doi.org/10.1111/j.1742-4658.2009.07332.x

[15] Klionsky, D.J., Baehrecke, E.H., Brumell, J.H., Chu, C.T., Codogno, P., Cuervo, A.M., et al. (2011) A Comprehensive Glossary of Autophagy-Related Molecules and Processes (2nd Edition). Autophagy, 7, 1273-1294. http://dx.doi.org/10.4161/auto.7.11.17661

[16] Galluzzi, L., Pietrocola, F., Bravo-San, P.J., Amaravadi, R.K., Baehrecke, E.H., Cecconi, F., et al. (2015) Autophagy in Malignant Transformation and Cancer Progression. EMBO Journal, 34, 856-880. http://dx.doi.org/10.15252/embj.201490784

[17] Levine, B. (2007) Cell Biology: Autophagy and Cancer. Nature, 446, 745-747. http://dx.doi.org/10.1038/446745a 